\title{
Vision Payment Claims Analyses with Health
}

\section{Insurance}

\author{
AARON HOUSTON MPH ${ }^{1}$, JOSEPH RUSKIWEWICZ, OD, $\mathrm{MPH}^{2}$, JOHN GAAL MHA², \\ CHAITALI BAVISKAR MHSA ${ }^{2}$, ATIYA LATIEMR ${ }^{2}$ \\ ${ }^{1}$ College of Public Health, Temple University \\ ${ }^{2}$ College of Optometry Eye Institute, Salus University Oak Lane Campus \\ Correspondence: aaron.houston@,temple.edu (Aaron L. Houston)
}

The purpose of this study was to identify associations between insurance type and out-of-pocket costs to rip code and income level. This was a cross-sectional study, using secondary data analyses. The study was completed at The Eye Institute (TEI) East Oak Lane Campus in Philadelphia, PA. The study population was all patients seen at TEI East Oak Lane Campus, from January 1st, 2019, to December 31st, 2019, whose encounter generated an insurance claim $(n=68,484)$. The exposure was insurance type, and the outcome was out-of-pocket costs. Data analyses were performed using $S A S$, version 9.4. In all statistical analyses, pvalues were one-sided and considered statistically significant if 0.05 or lower. The study protocol was approved by the Institutional Review Boards of Salus University. The sample represented an older population with an average age of about 55. There was a significant association found between insurance type and out-of-pocket costs $(p<0.0001)$. People with managed Preferred Provider Organization (PPO) pay the least, while those on Medicaid and Workers' Compensation pay the most out of pocket. 12 zip codes were studied. The two Philadelphia zip codes which pay the most out of pocket have two of the lowest average household incomes. Out-of-pocket expenses vary by insurance type with lower-income rip codes paying more which can potentially have a negative effect on patient vision health and access to care. These findings contribute to the identification of variables that influence an individual's healthcare and evidence for opportunities to improve insurance coverage accessibility.

Keywords: affordability, claims, healthcare, insurance, vision

\section{Introduction}

There are 31 million underinsured Americans who do not make enough income to pay for their medical expenses. ${ }^{1}$ This means they cannot afford to pay for prescribed treatments, to pay for recommended tests, or to avoid going into debt over medical bills. A person is considered underinsured if out-of-pocket health care costs exceed ten percent of their income ${ }^{1}$. Health insurance that provides more extensive coverage of preventive and screening services is likely to result in greater and more appropriate use of these services by patients. ${ }^{2}$ In 2017 , more than 93 million US adults were at high risk for vision loss compared with almost 65 million in 2002. ${ }^{0}$. However, only $56.9 \%$ visited an eye care professional annually, and only 59.8\% received a dilated eye examination. Among adults who reported needing eyeglasses, approximately $9 \%$ said they could not afford them, up slightly from $2002 .{ }^{0}$

The overall estimated morbidity of uncorrectable visual impairment in the U.S. 
population among individuals ages 40 and older was $2.14 \% .{ }^{12}$ Deaths can be related specifically to vison-related disease or infection complications. In Siantar's 2015 study, the relationship between visual impairment and agerelated eye diseases with mortality was studied. They concluded that diabetic retinopathy and retinal vein occlusion were markers of cardiovascular disease and associated with increased cardiovascular disease mortality. ${ }^{11}$ This suggests that visual impairment can be a predictor for chronic diseases such as cardiovascular disease.

Moreover, there are barriers present that influence individual's healthcare coverage. such as employment status, transportation to clinics that accept certain insurance, and cost of insurance/ healthcare services. Also, not all employers offer vison benefits. Employment status is a factor since the cost of eye care may be non-trivial for low-or no-income adults suggesting that having vision insurance may increase the use of care substantially and the overall health of the patient ${ }^{3}$. The average annual deductible for single, individual coverage is $\$ 4,364$ and $\$ 8,439$ for family coverage..$^{6}$ Indeed, the average deductible or employer coverage has grown seven times faster than workers' wages since $2010^{5}$. Vision coverage is currently an add-on benefit, which is often not covered by employment-based health insurance plans, and one of the first benefits to be eliminated to lower health insurance costs ${ }^{7}$. However, vision loss and impairment have been tied to several other health complications and co-morbidities. According to the Centers for Disease Control and prevention ${ }^{4}$, people with vision loss are more likely to report depression, diabetes, hearing impairment, stroke, falls, cognitive decline, and premature death. These all may play a role in the type of coverage one

\section{Materials and Methods}

This was a cross-sectional study: using a secondary data analysis. The study was completed at The Eye Institute (TEI) East Oak Lane Campus in Philadelphia, PA can get and the risks of higher payment costs in comparison to others without preexisting conditions.

According to a study by Winkelman ${ }^{13}$, enrollment in Medicaid, a government-funded program that covers health care costs for lowincome individuals and families in the United States, increased from 35 million to over 74 million between 2000 and $2017^{3}$. However, it should be noted that not every state offers the same coverage for vision. Still, enrollment in Medicaid was associated with significant increases in total medical spending and reductions in out-of-pocket costs, higher levels of prescription medication use, and improvements in access to care relative to individuals who remained uninsured ${ }^{4}$. The Patient Protection and Affordable Care Act (ACA), significantly increased Medicaid enrollment in some states and not others, creating natural experiments to study the population-level impact of Medicaid. A large body of evidence stemming from these experiments suggests Medicaid has positive effects on access to care, health, and financial security ${ }^{13}$.

In this study, financial class consisted of 22 different insurance types. Vison, the financial class with the highest frequency of claims, reflected only Medicaid Managed Care claims. It consisted of a combined group of insurers such as Davis vision, EyeMed, Vision benefits of America, UHC, Aetna, Cigna National Vision Administrator and HealthPartners. Age and race acted as moderating variables for whether a stronger relationship was present. Income level was the mediating variable and was ranked lowest to highest by zip code. The 12 chosen zip codes had the highest number of claims to study.

for approximately nine months from August 2020-April 2021. The study population was all patients seen at TEI East Oak Lane Campus, specifically patients seen 
at TEI clinic from January 1st, 2019, - to December 31st, 2019, whose encounter generated an insurance claim $(\mathrm{n}=68,484)$. Inclusion criteria were patients who came in for a visit. The exposure was insurance type and outcomes were patient total amount, billed amount, and payment amount by patient. The study protocol was approved by the Institutional Review Boards of Salus University.

Data analyses were performed using SAS, version $9.4^{9}$. In all statistical analyses, p-values were one-sided and considered statistically significant if 0.05 or lower. Patient amount, billed amount and pay amount were the dependent variables. From the acquired data, the statistical analysis included logistic regression and ANOVAcomparison between the insurance types using chi-square test was performed for associations between insurance type and costs. The primary dependent variables were patient total amount $(\mathrm{p}<0.0001)$, billed amount, $(\mathrm{p}<0.0001)$, and payment amount, $(p<0.0001)$. Other descriptive variables, such as race, age, and sex, compiled subject characteristics were used in analyses. Overall, analyses examined the claim amounts by the financial class at TEI East Oak Lane branch in Philadelphia to determine a relationship between out-ofpocket costs and income. This research applies towards the public health implications of possible variables which influence individuals' healthcare accessibility and affordability.

\section{Results}

Table 1 reports the descriptive statistics by age, sex, race, and financial class of claims reported at TEI from January 1st, 2019 - to December 31st, 2019. Overall, the sample represented an older population with an average age of about 55. Most of the
Table 1.

Descriptive Statistics by age, sex, race, and financial class of claims reported at TEI from January 1st, 2019 December 31st, 2019.

\begin{tabular}{|c|c|}
\hline \multicolumn{2}{|c|}{ Total N (\%) } \\
\hline Total & 68484 \\
\hline Age (Mean \pm Std Dev) & $54.87 \pm 24.32$ \\
\hline \multicolumn{2}{|l|}{ Sex } \\
\hline Female & $43019(62.84 \%)$ \\
\hline Male & $25426(37.14 \%)$ \\
\hline Unknown & $11(.02 \%)$ \\
\hline Missing & 28 \\
\hline \multicolumn{2}{|l|}{ Race } \\
\hline Black & $52672(80.3 \%)$ \\
\hline Other & $5362(8.1 \%)$ \\
\hline White & $5162(8 \%)$ \\
\hline Declined to say & $1249(1.9 \%)$ \\
\hline Asian & $784(1.12 \%)$ \\
\hline American Indian or & $216(.33 \%)$ \\
\hline \multicolumn{2}{|l|}{ Alaska } \\
\hline Hawaiian & $167(.25 \%)$ \\
\hline Missing & 2902 \\
\hline \multicolumn{2}{|l|}{ Financial Class } \\
\hline Vision & $26442(38.63 \%)$ \\
\hline Blue Cross & $14480(21.15 \%)$ \\
\hline Medicare & $13042(19.05 \%)$ \\
\hline Commercial & $4675(6.83 \%)$ \\
\hline Managed Medicare & $2393(3.50 \%)$ \\
\hline Medicaid & $2195(3.21 \%)$ \\
\hline No Insurance Adj & $1198(1.75 \%)$ \\
\hline Grant & $1075(1.57 \%)$ \\
\hline Invoice Billing & $1044(1.53 \%)$ \\
\hline BCBS PPO & $324(.47 \%)$ \\
\hline Self-Pay & $320(.47 \%)$ \\
\hline Student Benefits & $317(.46 \%)$ \\
\hline Grant-Low Vision & $305(.45 \%)$ \\
\hline School Program & $190(.28 \%)$ \\
\hline Employee Benefit & $153(.22 \%)$ \\
\hline Work Comp & $90(.13 \%)$ \\
\hline Medical Records & $74(.11 \%)$ \\
\hline Auto (MVA) & $51(.07 \%)$ \\
\hline Managed HMO & $43(.06 \%)$ \\
\hline Other & $27(.04 \%)$ \\
\hline Managed PPO & $18(.03 \%)$ \\
\hline Missing & 28 \\
\hline
\end{tabular}

claims were generated by Black people $(80.3 \%)$ and the majority female $(62.8 \%)$. The highest frequency of claims came from the vision class as mentioned in the table $(38.63 \%)$. The second-highest number of 
claims came from Blue Cross (21\%). Medicare is third, covering $19 \%$ of the claims generated. Overall, those three categories of insurers covered approximately $80 \%$ of the insurance claims

generated. In each of the ANOVA tests (Table 2), there is a significant association between financial class, patient amount, billed amount, and payment amount. No correlations were run. Equally, the F values show that there was a significant difference as well.
In detail, Table 3 breaks down the average patient number of clams by financial class by a means analysis. As shown, those on a Managed PPO paid the least, followed by those with Other, while those with Workers Compensation and Medicaid paid the most out of pocket. The second highest paying out-of-pocket insurance type is Medicaid. However, Vision class patients pay significantly less on average that Medicaid patients. Again, Vision (38.63\%) is used to reflect only Medicaid Managed Care as

Table 2.

One-W ay Analysis of V ariance (ANOV A) by financial class of patient amount, billed amount, and payment amount.

\begin{tabular}{ccccccc}
\hline $\begin{array}{c}\text { Dependent } \\
\text { Variables }\end{array}$ & Mean \pm Std Dev & Source & $\begin{array}{c}\text { Sum of } \\
\text { Squares }\end{array}$ & DF & $\begin{array}{c}\text { Mean of } \\
\text { Squares }\end{array}$ & $\begin{array}{c}\text { One-Way } \\
\text { ANOVA }\end{array}$ \\
\hline & & & & & F & P-value \\
Patient Amount & $\$ 1.23 \pm \$ 15.44$ & Financial Class & 149116.27 & 20 & 7455.81 & 31.57 \\
Billed Amount & $\$ 11.05 \pm \$ 100.76$ & Financial Class & 11407199.3 & 20 & 570360 & 57.10 \\
Pay Amount & $-\$ 34.84 \pm \$ 52.09$ & Financial Class & 15751152.8 & 20 & 787557.6 & 316.97
\end{tabular}

* A negative amount represents dollars received.

* The patient amount variable is the amount paid by the patient out of pocket.

*The billed amount is the total amount billed for the service.

*Pay amount is the amount that was paid in total by the financial class and patient.

Table 3.

Average patient amount by financial class

\begin{tabular}{|c|c|c|c|c|}
\hline Financial Class & $\begin{array}{c}\text { Total } \\
\text { Claims }\end{array}$ & Mean \pm Std Dev & $\begin{array}{l}\text { Minimum Claim } \\
\text { Amount }\end{array}$ & $\begin{array}{c}\text { Maximum Claim } \\
\text { Amount }\end{array}$ \\
\hline Vision & 26442 & $\$ 0.8888889 \pm \$ 15.7247147$ & $-\$ 405.0000000$ & $\$ 450.0000000$ \\
\hline Blue Cross & 14480 & $\$ 0.5365331 \pm \$ 13.8018164$ & $-\$ 265.0000000$ & $\$ 325.0000000$ \\
\hline Medicare & 13042 & $\$ 1.6097224 \pm \$ 12.4053521$ & $-\$ 155.0000000$ & $\$ 258.0000000$ \\
\hline Commercial & 4675 & $\$ 2.8188235 \pm \$ 20.4654626$ & $-\$ 100.0000000$ & $\$ 549.0000000$ \\
\hline Managed Medicare & 2393 & $-\$ 0.1512746 \pm \$ 16.3376430$ & $-\$ 166.0000000$ & $\$ 147.0000000$ \\
\hline Medicaid & 2195 & $\$ 7.4236902 \pm \$ 25.7403943$ & $-\$ 67.0000000$ & $\$ 211.0000000$ \\
\hline No Insurance Adj & 1198 & $-\$ 0.4766277 \pm \$ 15.4377194$ & $-\$ 300.0000000$ & $\$ 140.0000000$ \\
\hline Grant & 1075 & $0 \pm 0$ & 0 & 0 \\
\hline Invoice Billing & 1044 & $-\$ 0.1024904 \pm \$ 1.9381702$ & $-\$ 40.0000000$ & 0 \\
\hline BCBS PPO & 324 & $\$ 4.8487654 \pm \$ 29.7136796$ & $-\$ 171.0000000$ & $\$ 128.0000000$ \\
\hline Self-Pay & 320 & $0.5312500 \pm 15.9483578$ & $-\$ 158.0000000$ & $\$ 118.0000000$ \\
\hline Student Benefits & 317 & $0 \pm 0$ & 0 & 0 \\
\hline Grant-Low Vision & 305 & $0 \pm 0$ & 0 & 0 \\
\hline School Program & 190 & $0 \pm 0$ & 0 & 0 \\
\hline Employee Benefit & 153 & $\$ 1.9150327 \pm \$ 14.0154744$ & 0 & $\$ 115.0000000$ \\
\hline Work Comp & 90 & $\$ 16.0666667 \pm \$ 32.6482100$ & 0 & $\$ 188.0000000$ \\
\hline Medical Records & 74 & $0 \pm 0$ & 0 & 0 \\
\hline Auto (MVA) & 51 & $0 \pm 0$ & 0 & 0 \\
\hline Managed HMO & 43 & $\$ 3.7674419 \pm \$ 9.4964585$ & 0 & $\$ 29.0000000$ \\
\hline Other & 27 & $-\$ 4.8148148 \pm \$ 15.7895706$ & $-\$ 48.0000000$ & $\$ 14.0000000$ \\
\hline
\end{tabular}

*Financial Class is insurance type. 
payer. So, those who patients who receive Medicaid benefits through a Managed Care Plan pay less on average than patients who have plain Medicaid (3.21\%) at TEI.

Table 4 shows the top Philadelphia zip codes by average patient amount, payment amount. Claims by people who resided in 19140 paid the most on average out of pocket, followed by those in 19124, while those in 19119 and 19132 paid the least. average household incomes in comparison to the rest of the zip codes listed. As shown, the zip codes that have the highest-ranked average patient amounts include 19140, 19124, and 19120. The zip codes with the lowest-ranked average household income are 19132,19140 , and $19144 .{ }^{15}$ The zip code with the lowest average income, 19132, paid the lowest on average out of pocket, $(\$ .77 \pm$ $\$ 14.57)$. While the zip code with the second

Table 4.
\begin{tabular}{cccc} 
The top patient zip codes on claims by average patient amount and payment amount. & \\
\hline Zip Code & Patient Amount & Pay Amount & Total claims \\
\hline 19140 & $\$ 2.71 \pm \$ 19.60$ & $-\$ 33.02 \pm \$ 46.69$ & 3356 \\
19124 & $\$ 2.27 \pm \$ 16.21$ & $-\$ 34.80 \pm \$ 58.90$ & 1913 \\
19120 & $\$ 1.77 \pm \$ 14.49$ & $-\$ 31.70 \pm \$ 44.86$ & 6402 \\
19126 & $\$ 1.46 \pm \$ 17.78$ & $-\$ 33.29 \pm \$ 38.93$ & 3769 \\
19138 & $\$ 1.37 \pm \$ 14.8$ & $-\$ 33.37 \pm \$ 43.03$ & 7086 \\
19111 & $\$ 1.25 \pm \$ 16.46$ & $-\$ 31.55 \pm \$ 40.68$ & 2283 \\
19150 & $\$ 1.18 \pm \$ 15.58$ & $-\$ 34.28 \pm \$ 36.96$ & 5221 \\
19144 & $\$ 1.09 \pm \$ 12.76$ & $-\$ 33.63 \pm \$ 46.52$ & 4312 \\
19141 & $\$ 1.08 \pm \$ 12.99$ & $-\$ 33.56 \pm \$ 41.44$ & 6677 \\
19119 & $\$ .77 \pm \$ 16.28$ & $-\$ 38.92 \pm \$ 66.19$ & 2447 \\
19132 & $\$ .77 \pm \$ 14.57$ & $-\$ 35.15 \pm \$ 49.19$ & 1885 \\
19149 & $\$ .99 \pm \$ 12.66$ & $-\$ 33.09 \pm \$ 46.00$ & 1318
\end{tabular}

Table 5 ranks zip codes by patient amount, highest to lowest, and avg household income, least to greatest, and shows how they align with each other. However, those zip codes that paid the most on average for patient amounts also had two of the lowest lowest average income 19140, paid the most out of pocket on average $(\$ 2.71 \pm \$ 19.60)$.

To summarize, there was a significant association found between financial class with patient total amount $(\mathrm{p}<0.0001)$, billed amount $(\mathrm{p}<0.0001)$, and

\begin{tabular}{lcc}
\hline $\begin{array}{l}\text { Table } 5 . \\
\text { Ranks the amount paid and the avg household income to demonstrate how they align with each other. Average bousehold income } \\
\text { data from 2009-2013 was taken from the Philadelphia Inquirer. }\end{array}$ \\
\hline Zip Code & Patient Amount Rank* & Avg Household Income Rank** \\
\hline 19140 & 1 & 2 \\
19124 & 2 & 4 \\
19120 & 3 & 7 \\
19126 & 4 & 8 \\
19138 & 5 & 6 \\
19111 & 6 & 10 \\
19150 & 7 & 11 \\
19141 & 8 & 5 \\
19144 & 9 & 3 \\
19149 & 10 & 9 \\
19119 & 11 & 12 \\
\hline
\end{tabular}

* - ranked highest to lowest amount paid by the patient ** - ranked lowest to highest average household income 
pay amount $(\mathrm{p}<0.0001)$. People with managed PPO paid the least, while those on Medicaid and workers' compensation paid the most out of pocket. The two Philadelphia zip codes which paid the most out of pocket had two of the lowest average household incomes in the Greater

\section{Discussion}

The study intended to measure associations, if any, between insurance type, out-of-pocket costs, and income of individuals' access to adequate coverage. The hypothesis was that there would be a direct relationship between income and outof-pocket costs. For example, as out-ofpocket costs went up, the patient's income would go up and vice versa. Total out-ofpocket health care costs can vary depending on the service billed and type of health insurance coverage, employment, income, age of the patient. All are viable factors in determining one's health insurance coverage and overall charges, therefore influencing out-of-pocket costs as well.

A significant association was found between financial class and out-of-pocket costs by the patient at TEI Oak Lane campus. Individuals with Workers Compensation, a form of insurance that provides medical expense costs to employees and families of employees who are injured, sick, or are killed on the job, are paid the most out of pocket in the total paid amount. Medicaid, government insurance for low-income individuals and households, paid the second most out of pocket in total patient costs. Again, these are individuals who had only Medicaid and are not enrolled in a managed care plan. Medicaid. There may be incentive for patients to select a Medicaid Managed Care Plan vs. Medicaid if there is a significant difference in out-ofpocket costs. These insurance types
Philadelphia area. If Vision (39\%) is used to report only Medicaid Managed Care as payor, can contrast the out-of-pocket expense for this group of Medicaid patients vs. the straight Medicaid patients [3.21\% of claims]).

represent disabled and impoverished groups who tend to lack access to affordable and adequate health insurance. Among a national sample of uninsured individuals, Medicaid enrollment was associated with substantial favorable changes in out-ofpocket costs, prescription drug use, and access to care. Winkelman ${ }^{13}$ findings suggest Medicaid is an important tool to reduce insurance-related disparities among Americans ${ }^{14}$. Of course, it would be expected that these individuals would pay the least amount of money as compared to other insurance types in out-of-pocket costs. However, as presented in the results, this is not the case. This implies that the lowest income households do not always pay the lowest out-of-pocket expenses.

Evidence linking specific features of neighborhood social environments to health outcomes and insurance accessibility is more difficult to summarize than evidence for the effects of physical environments on health. From 1999 to 2008, individuals with less education and lower income were consistently less likely to have had an eye care visit in the past 12 months compared with their counterparts. During this period, the inability to afford needed eyeglasses increased among non-Hispanic whites and those with high school education ${ }^{14}$. The TEI serves a diversity of patients between its many clinic locations throughout the city of Philadelphia. Generally, most of the insurance claims generated during the study 
period were by Black people and women. This could be due to only one clinic location being included in the study and the location of the clinic being in a majority Black residential and low-income area. It is possible that if the study were to include multiple years and different clinic locations, the diversity and socioeconomic status of the results would be different, suggesting that the location is a potential effect modifier in the results. Even so, the results suggest that the type of health insurance is significantly associated with total out-ofpocket costs for the patient.

Also, insurance type and out-ofpocket expenses seem to be different depending on the income of the patient and their race. The three Philadelphia zip codes with the highest total amount paid by the patient, had three of the lowest average household incomes. Uniformly low socioeconomic status, coupled with a high

\section{Limitations}

The study has several limitations that should be considered in the interpretation of the results. The biggest limitation is that the Vison Financial class composition includes many patients with a Medicaid Managed Care Plan which misses patients not classified in the Medicaid or Managed Medicare class category. Also, TEI has several clinics across the Philadelphia area. The analyses used only one clinic in a predominantly Black residential area that provided a homogenous group that limits

\section{Conclusion}

Overall, the study results suggest several implications for public health. The clinical relevance of these findings identifies variables, such as zip code, income and employment that influence healthcare costs proportion of minorities $(86 \%$ of the sample) indicates a sample that would expect to be at greatly increased risk for blindness and visual impairment compared to the general population ${ }^{1}$. During the observed 12-month study, most of the payment claims were from Black patients; nonetheless, there is still no reason for them to pay the most on average inpatient amount. Excess payment with the inability to pay put a greater financial burden on already working low-income people and influences accessibility which affects the health of Philadelphians. America recognizes now more than ever that racism and discrimination are deeply ingrained in the social, political, and economic structures of our society. For minorities, these differences result in unequal access to quality education, healthy food, livable wages, and affordable insurance . $^{8}$

the ability to identify the potential impact race of and income relative to mainstream communities. It is therefore notable that among persons from the same communities and of similar socioeconomic status, race and ethnicity are not significant differentiating factors between these two groups. Also, the brevity of the data collection period limited the number of claims that were able to be observed and analyzed over the chosen study period.

and evidence for opportunities to improve insurance coverage affordability. In some cases, lower average household income zip codes tend to pay more out of pocket for health insurance in comparison to higher 
income households. There should be more federal and local policy put in place to help assist health insurance costs since it has been shown to be beneficial over the years.
Also, the insurance enrollment requirements should be broader to increase accessibility among the population, and it should cover more eye care services

\section{Conflicts of Interest}

The authors have no conflicts to disclose.

\section{Statement of Contributions}

Aaron Houston conceived the idea for this study, study design, data analysis, data organization and drafted the manuscript. Joseph Ruskiwewicz helped conceive the idea for this study. John Gaal assisted with data analysis, and provided input on all aspects of the manuscript. Chaitali Baviskar and Atiya Latimer analyzed and organized the data.

\section{References}

1. Health Well Foundation. (2017). Underinsured Americans Need a Financial Lifeline. https://www.healthwellfoundation.org/wpcontent/uploads/2017/10/Underinsurance_In_Americ a.HWF_.2015.pdf.

2. Bond, K. G. (2002). National Academy Press. Institute of Medicine (US) Committee on the Consequences of Insurance. Effects of Health Insurance on Health. Care without coverage: Too little, too late...: National Academies Press (US); 2002. PMID: 25057604.

3. Brandy J. Lipton, Sandra L. Decker, (2015) The effect of health insurance coverage on medical care utilization and health outcomes: Evidence from Medicaid adult vision benefits, Journal of Health Economics, Volume 44,2015,Pages 320-332,ISSN 0167-6296, https://doi.org/10.1016/j.jhealeco.2015.10.006.

4. Centers for Disease Control and Prevention. Vision Loss: A Public Health Problem. (2020, June 12). Retrieved October 02, 2020, from https://www.cdc.gov/visionhealth/basic_information/vision_loss.htm

5. Clinton, H. (2016). My vision for universal, quality, affordable health care. The New England Journal of Medicine, 375(17) doi:http://dx.doi.org.libproxy.temple.edu/10.1056/NEJMsb1612292

6. Baker, R. S., Bazargan, M., Bazargan-Hejazi, S., \& Calderón, J. L. (2005). Access to Vision Care in an Urban Low-Income Multiethnic Population. Ophthalmic Epidemiology, 12(1), 1-12. https://doi.org/10.1080/09286580590921330

7. Li Y, Xirasagar S, Pumkam C, Krishnaswamy M, Bennett CL.(2013) Vision Insurance, Eye Care Visits, and Vision Impairment Among Working-Age Adults in the United States. JAMA Ophthalmol. 2013;131(4):499-506. doi:10.1001/jamaophthalmol.2013.1165

8. MPH, M. T., MD. (2017, January 16). Racism and discrimination in health care: Providers and patients. Harvard Health Blog. https://www.health.harvard.edu/blog/racism-discrimination-health-careproviders-patients-2017011611015

9. SAS 9.4 Software. (n.d.). Retrieved April 29, 2019, from https://www.sas.com/en_us/software/sas9.html

10. Saydah SH, Gerzoff RB, Saaddine JB, Zhang X, Cotch MF.(2017) Eye Care Among US Adults at High Risk for Vision Loss in the United States in 2002 and 2017. JAMA Ophthalmol. 2020;138(5):479-489. doi:10.1001/jamaophthalmol.2020.0273

11. Siantar, R. G., Cheng, C. Y., Gemmy Cheung, C. M., Lamoureux, E. L., Ong, P. G., Chow, K.Y., Mitchell, P., Aung, T., Wong, T. Y., \& Cheung, C. Y. (2015). Impact of Visual Impairment and Eye diseases on Mortality: the Singapore Malay Eye Study (SiMES). Scientific reports, 5, 16304. https://doi.org/10.1038/srep16304 
12. Varma, R., Vajaranant, T. S., Burkemper, B., Wu, S., Torres, M., Hsu, C., Choudhury, F., \& McKeanCowdin, R. (2016). Visual Impairment and Blindness in Adults in the United States: Demographic and Geographic Variations From 2015 to 2050. JAMA ophthalmology, 134(7), 802-809. https://doi.org/10.1001/jamaophthalmol.2016.1284

13. Winkelman TNA, Segel JE, Davis MM. Medicaid enrollment among previously uninsured Americans and associated outcomes by race/ethnicity-United States, 2008-2014. Health Serv Res. 2019 Feb;54 Suppl 1(Suppl 1):297-306. doi: 10.1111/1475-6773.13085. Epub 2018 Nov 5. PMID: 30394525; PMCID: PMC6341200.

14. Zhang, X., Cotch, M. F., Ryskulova, A., Primo, S. A., Nair, P., Chou, C., Saaddine, J. B. (2012). Vision health disparities in the United States by Race/Ethnicity, education, and economic status: Findings from two nationally representative surveys. American Journal of Ophthalmology, 154(6), S53-S62.e1. doi:http://dx.doi.org.libproxy.temple.edu/10.1016/j.ajo.2011.08.045

15. The Philadelphia Inquirer. Map: Income and Poverty in the Philadelphia Region - Philly. (2014, December 5). //www.philly.com/philly/infographics/medianincome.html

16. Poretta, A. (2020, November 8). How much does individual health insurance cost? - ehealth ... EHealthinsurance. $\quad$ Retrieved $\quad$ October 2021, from https://www.ehealthinsurance.com/resources/individual-and-family/how-much-does-individualhealth-insurance-cost. 